\title{
Protein kinase and phosphatase control of plant temperature
} responses

\author{
Myrthe Praat ${ }^{1}$, Ive De Smet ${ }^{2,3,(\mathbb{D})}$ and Martijn van Zanten ${ }^{1, *,(\mathbb{D})}$ \\ ${ }^{1}$ Molecular Plant Physiology, Institute of Environmental Biology, Utrecht University, Padualaan 8, 3584CH Utrecht, the Netherlands \\ ${ }^{2}$ Ghent University, Department of Plant Biotechnology and Bioinformatics, B-9052 Ghent, Belgium \\ ${ }^{3}$ VIB Center for Plant Systems Biology, B-9052 Ghent, Belgium \\ * Correspondence: m.vanzanten@uu.nl
}

Received 29 March 2021; Editorial decision 19 July 2021; Accepted 20 July 2021

Editor: Steve Penfield, John Innes Centre, UK

\begin{abstract}
Plants must cope with ever-changing temperature conditions in their environment. Suboptimal high and low temperatures and stressful extreme temperatures induce adaptive mechanisms that allow optimal performance and survival, respectively. These processes have been extensively studied at the physiological, transcriptional, and (epi) genetic level. Cellular temperature signalling cascades and tolerance mechanisms also involve post-translational modifications (PTMs), particularly protein phosphorylation. Many protein kinases are known to be involved in cold acclimation and heat stress responsiveness, but the role and importance of kinases and phosphatases in triggering responses to mild changes in temperature, such as thermomorphogenesis, are inadequately understood. In this review, we summarize current knowledge on the roles of kinases and phosphatases in plant temperature responses. We discuss how kinases can function over a range of temperatures in different signalling pathways and provide an outlook to the application of PTM-modifying factors for the development of thermotolerant crops.
\end{abstract}

Keywords: Cold acclimation, heat stress, kinases, phosphatases, temperature acclimation, thermomorphogenesis

\section{Introduction}

Plants are remarkably sensitive to small changes in ambient temperature and respond to both cold and warmth (Chinnusamy et al., 2010; Quint et al., 2016). Understanding and adjusting plant responsiveness to mild changes in ambient temperature will be a major challenge for the future, since an increase of the average global temperature (global warming) will affect agricultural productivity and ecosystem functioning (Stocker et al., 2013). Already a $1{ }^{\circ} \mathrm{C}$ increase in average global temperature is predicted to lead to major yield losses in staple crops such as wheat, maize, and rice (Battisti and Naylor, 2009; Craufurd and Wheeler, 2009; Challinor et al., 2014; Zhu et al., 2021). In addition, climate change will prompt more irregular weather events such as colder winters and more frequent heat waves and droughts (Battisti and Naylor, 2009).

Plant responses to temperature can be roughly classified along the temperature gradient (Penfield, 2008) (Fig. 1) and has a direct effect on the speed of plant development, also referred to as the thermal time concept, which is especially 


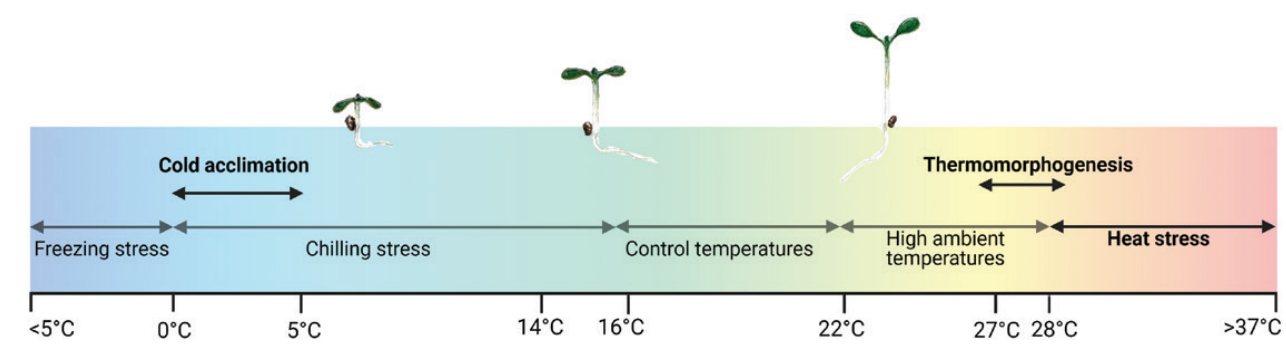

Fig. 1. Temperature tolerance and acclimation processes along the temperature gradient in Arabidopsis. Temperature responses discussed in this review - cold acclimation, thermomorphogenesis, and heat stress-are highlighted in bold. The seedlings depict the effect of different temperatures on hypocotyl elongation and leaf position. At cold temperatures the seedlings grow slowly and stay short. At high ambient temperatures the hypocotyl elongates and leaves become hyponastic, these being the first visual signs of thermomorphogenesis. 'Control temperatures' refer to the conditions in which Arabidopsis is typically cultivated in laboratories world-wide.

clear in flowering time (Parent et al., 2019). When experiencing temperatures at either extreme of the gradient, i.e. cold/ freezing or heat stress, plants typically exhibit stress responses to tolerate the stressful environment by constraining growth and development (van Zanten et al., 2009b; Parent and Tardieu, 2012). The model species Arabidopsis experiences chilling stress when temperatures drop to around $14{ }^{\circ} \mathrm{C}$ and lower, but significant variation is present in Arabidopsis (Zuther et al., 2012). Chilling stress leads to reduced growth and a compact form (Hasdai et al., 2006). However, damage is most severe when plants experience cold stress (Hasdai et al., 2006), which typically causes irreversible damage as membrane integrity and metabolic and homeostatic processes are disrupted and cells dehydrate (Chinnusamy et al., 2007, 2010; Moellering et al., 2010). Freezing-induced $\left(<0{ }^{\circ} \mathrm{C}\right)$ injuries are typically caused by intracellular ice formation (Thomashow, 1999). However, Arabidopsis plants can become cold tolerant after an acclimation period at $0-5{ }^{\circ} \mathrm{C}$ in a process dubbed cold acclimation (Thomashow, 1999).

Plants can respond to heat stress in different manners, roughly defined as basal thermotolerance and acquired thermotolerance (Sung et al., 2003; Larkindale et al., 2005; Yoo et al., 2006). Pre-exposure of plants to sub-lethal high temperatures for a certain period leads to a significantly increased tolerance to otherwise lethal heat stress. This is called acquired thermotolerance, a term that can also apply to freezing stress (Sung et al., 2003). Intrinsic capacity to withstand heat stress is referred to as basal thermotolerance (Yoo et al., 2006).

Heat stress is characterized by increased oxidative damage, rapid cell death, and damage to chloroplasts and photosynthesis processes (Hu et al., 2020) and is one of the major environmental threats for crop yield (Lobell and Gourdji, 2012). Characteristic symptoms of heat stress are, among others, reduced fertility, reduced seed vigour and germination, growth inhibition, induction of leaf senescence and abscission, and reduced grain filling (reviewed in Sung et al., 2003; Kotak et al., 2007; Liu et al., 2015; Li et al., 2018).

Mild high temperatures usually do not inflict permanent damage and can therefore be considered a sub-optimal growth condition instead of stressful. The exact definition of mild warm temperature is obviously dependent on the species under consideration, as optimal growth temperatures greatly differ among plants from diverse climates (Yeh et al., 2012). For Arabidopsis in the research laboratory, however, mild warm temperatures are considered $26-29^{\circ} \mathrm{C}$ by convention, whereas usually control temperature conditions are $20-22{ }^{\circ} \mathrm{C}$ (Koini et al., 2009; Quint et al., 2016) (Fig. 1). For Arabidopsis, temperatures above $30^{\circ} \mathrm{C}$ typically are referred to as heat (Wahid et al., 2007).

Mild warm temperatures have an impact on many processes in plants including time of flowering, seed yield, root and shoot growth, and disease tolerances (Quint et al., 2016; Gangappa et al., 2017; Lamers et al., 2020; Zhu et al., 2021). Several species can acclimate to sub-optimal warmth to maintain (or enhance) their performance and reproductive fitness by adjusting their growth, architecture, and physiology. Together, the suite of morphological changes imposed by mild warm temperature is called thermomorphogenesis (Koini et al., 2009; Quint et al., 2016; Casal and Balasubramanian, 2019). Early signs of thermomorphogenesis in Arabidopsis include seedling hypocotyl elongation and leaf hyponasty (Fig. 1), which is observed in several accessions (Gray et al., 2002; Koini et al., 2009; Ibañez et al.,2017). Older thermomorphogenic Arabidopsis plants also, for example, display elongated petioles, contain fewer stomata, and the leaves become smaller and thinner (Koini et al., 2009; van Zanten et al., 2010). The resulting reduced boundary-layer thickness stimulates heat dissipation by evaporation and convection (reviewed in Quint et al., 2016). Altogether, the open rosette structure resulting from thermomorphogenic acclimation is thus proposed to aid the plant's cooling capacity and in addition allows avoidance of direct heat flux of the sun (Crawford et al., 2012; Bridge et al., 2013).

Temperature signalling mechanisms have been extensively studied at the transcriptional, (epi)genetic, and physiological (e.g. hormonal) levels (Chinnusamy et al., 2010; Eremina et al., 2016; Quint et al., 2016; Casal and Balasubramanian, 2019; Hu et al., 2020). However, the role of cellular signalling cascades involving protein post-translational modifications (PTMs) is less well-understood. There is a large diversity of PTMs, including protein phosphorylation, lysine ubiquitination, 
sumoylation, lysine acetylation, serine/threonine glycosylation, carbonylation, and cysteine nitrosylation (Kuo and Allis, 1998; Moller and Kristensen, 2004; Miura et al., 2007; Hochstrasser, 2010; Strasser, 2016; Vu et al., 2018a).

Reversible protein phosphorylation is one of the most common PTMs in plants and phosphorylated proteins (phosphoproteins) can affect protein activity, subcellular localization, interacting partners, and stability (Bhaskara et al., 2019). Protein phosphorylation is an enzymatically catalysed process that is enabled by kinases or phosphotransferases that transfer the $\gamma$-phosphate group of ATP to a functional group of serine, threonine, tyrosine, and histidine residues (Durek et al., 2009; Dissmeyer and Schnittger, 2011; van Wijk et al., 2014; Macho et al., 2015; Vu et al., 2018a). Phosphorylated proteins are targets of protein phosphates that enzymatically remove the phosphate group (Schweighofe and Meskiene, 2015).

PTMs are considered switchboxes for cellular signalling (Vu et al., 2018a) and provide a layer of information processing and signal transduction that operates autonomously from the genetic makeup of the organism (Prabakaran et al., 2012). PTMs thereby add another level of complexity to signalling networks and response mechanisms (Arsova et al., 2018). Interestingly, PTMs are among the fastest and earliest signalling events and therefore well-suited to quickly adjust cellular responses to environmental changes, particularly fluctuating temperatures. Indeed, protein (de)phosphorylation is one of the critical regulatory mechanisms in cellular signal transduction pathways modulating plant growth, development, and responses to the environment (Kline-Jonakin et al., 2011; Vu et al., 2018a).

It is estimated that Arabidopsis has approximately 1000 protein kinases (Wang et al., 2007; Smoly et al., 2017; Vu et al., 2018a). In contrast, only about 150 protein phosphatases have been annotated in the Arabidopsis genome (Smoly et al., 2017). This apparent odd balance between kinases and phosphatases is observed in all eukaryotes, but the ratio of at least five kinases to one phosphatase in Arabidopsis is notable (Wang et al., 2007). Due to this bias, research concerning protein phosphorylation has mainly concentrated on protein kinases.

In this review we focus on the role of kinases and phosphatases, and their target proteins, in temperature signalling and responses to changes in temperature in Arabidopsis and crop species. This knowledge can be instrumental in the development of thermotolerant crop varieties that can mitigate or tolerate suboptimal or stressful temperatures (Wahid et al., 2007).

\section{Kinase regulation of cold acclimation}

Freezing can cause lethal damage, but many plants can become cold tolerant following an acclimation period at $0-5{ }^{\circ} \mathrm{C}$ in the process of cold acclimation that involves reprogramming of gene expression (Thomashow, 1999; Chinnusamy et al., 2007, 2010). After cold acclimation, plants typically stay compact and display enhanced cellular protection that includes desaturation of membrane lipids, increased osmolyte levels, and adjustments of photosynthesis (Wanner and Junttila, 1999; Barnes et al., 2016).

A proteome analysis of the cold response in spring and winter wheat (Triticum aestivum) exemplifies the importance of PTMs in cold acclimation of crops (Kosová et al., 2013).Vernalization likely induces phosphorylation of JACALIN-LIKE LECTIN (VER2) and such phosphorylatedVER2 appears to be involved in $\mathrm{N}$-acetylglucosamine (O-GlcNAc) signalling during vernalization. Consistent with a role forVER2 in flowering (vegetative to reproductive phase transitions), higher levels of VER2 were observed in the spring cultivar (Kosová et al., 2013).

A well-investigated transcriptional cascade involved in cold acclimation of Arabidopsis is the ICE1-CBF-COR regulon (Fig. 2). In response to cold stress, the basic-helix-loop-helix type transcription factor INDUCER OF CBF EXPRESSION 1 (ICE1) binds to the promoter of C-REPEAT-BINDING FACTOR $(C B F)$ genes. The $C B F$ genes $(C B F 1, C B F 2$, and $C B F 3)$ are induced by cold stress and bind to the cis-element of the COLD RESPONSIVE (COR) genes, thereby activating $C O R$ gene expression. COR genes encode cryoprotective proteins that protect plant cells against cold-induced membrane damage (Thomashow, 1999). The activity of ICE1 is mainly regulated at the protein level and cold stress triggers ICE1 phosphorylation at Ser403 to stabilize the protein and activate the CBF regulon (Chinnusamy et al., 2003; Thomashow, 2010; Ding et al., 2015; Barrero-Gil and Salinas, 2017; Ramirez and Poppenberger, 2017). The regulation of the ICE1 protein by kinases will be further discussed below.

Interestingly, ICE1 is also expressed in warm temperatures, so ICE1 expression may not be solely associated to cold. Despite ICE1 overexpression enhancing cold induction of $C B F$, overexpression of ICE1 does not lead to CBF induction in warm temperature conditions. Whether and how ICE1 functions in warm temperature signalling and responses remains unknown.

\section{Regulation of cold acclimation through OST1}

Different protein kinases mediate the stability of proteins in the ICE1-CBF-COR cold signalling pathway, including the positive regulator of cold acclimation OPEN STOMATA 1 (OST1) (Mustilli et al., 2002; Ding et al., 2018b). OST1 is a Ser/Thr protein kinase that is a key component in abscisic acid (ABA) signalling and a regulator of stomatal aperture (Mustilli et al., 2002; Ding et al., 2018b). OST1 is activated by cold stress and positively regulates freezing tolerance via the ICE1-CBF-COR pathway in different ways (Fig. 2). First, OST1 modulates freezing tolerance by enhancing ICE1 protein stability in Arabidopsis (Ding et al., 2015). OST1 interacts with - and phosphorylates - the ICE1 protein. Moreover, OST1 competes with ICE1 for interaction with HIGH 


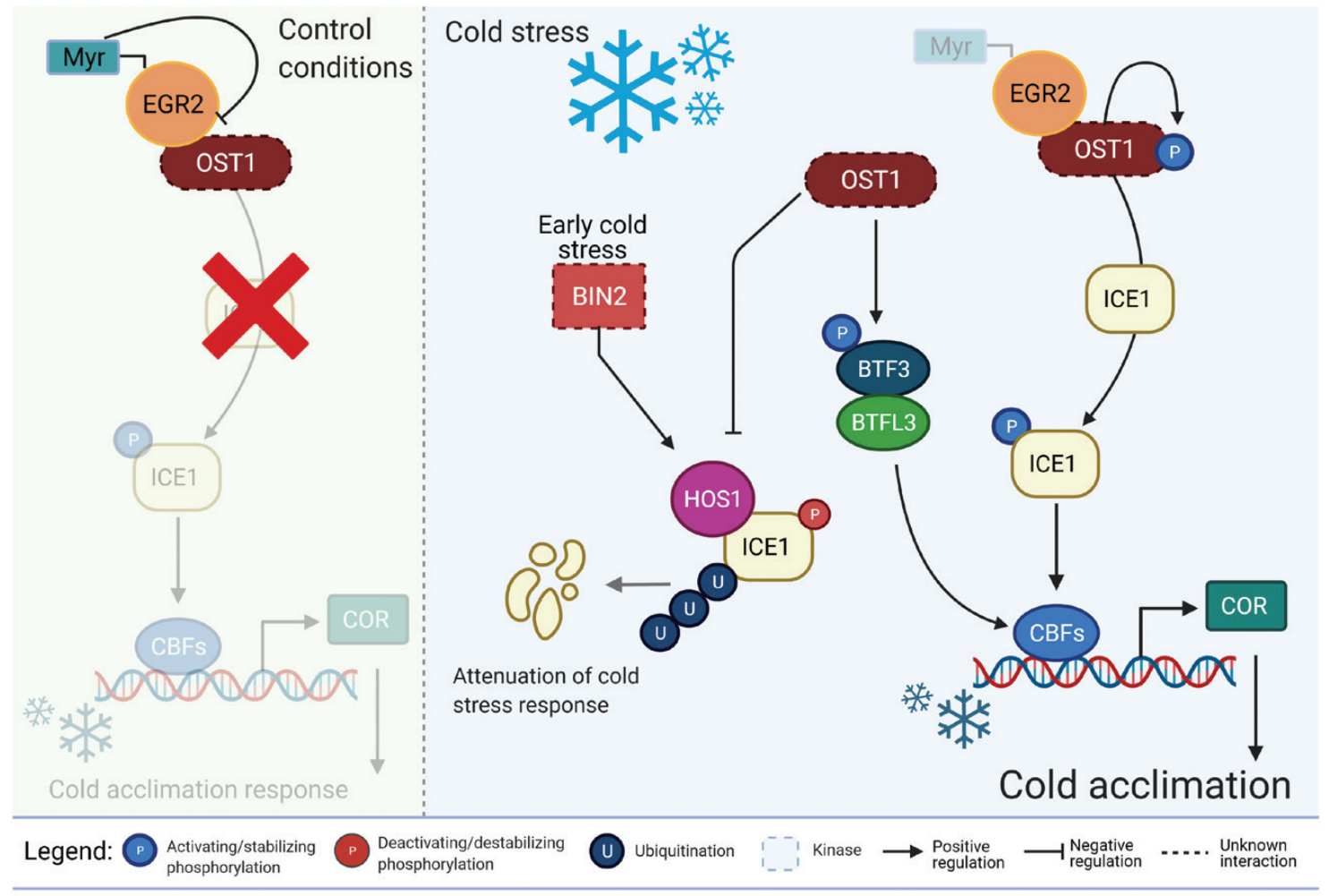

Fig. 2. Regulation of cold acclimation responses by phosphorylation. Under prolonged cold stress, the kinase BIN2 phosphorylates ICE1. Thereby interaction of ICE1 and HOS1 is facilitated, which promotes degradation of ICE1. OST1 interacts with-and phosphorylates - the ICE1 protein and competes with ICE1 for interaction with HOS1. By this means, OST1 suppresses HOS1-mediated ICE1 degradation. OST1 positively regulates cold acclimation by phosphorylating BTF3-BTFL3, thereby enhancing their stability. BTF3-BTFL3 in turn enhances CBF gene expression. OST1 is regulated by, and interacts with, a plasma membrane-localized clade-E growth-regulating 2 (EGR2) phosphatase, inhibiting the activity of OST1 under control temperatures. Under cold stress conditions, a myristoyl-switch (Myr) on EGR2 leads to the cold activation of OST1, as the interaction between OST1 and EGR2 is attenuated. OST1 is consequently activated and stabilizes the ICE1 protein by phosphorylation. The stabilized ICE1 protein enhances CBF gene expression and initiates the cold acclimation response. Symbols are explained at the bottom of the figure.

\section{EXPRESSION OF OSMOTICALLY RESPONSIVE} GENES 1 (HOS1). Such OST1 binding to HOS1 prevents HOS1-mediated ICE1 degradation (Ding et al., 2015). ost1 mutants are indeed hypersensitive to cold stress, and relative expression levels of $C B F$ genes in ost 1 mutants are significantly lower in both control and cold stress conditions (Ding et al., 2015). Second, OST1 positively regulates cold responses in Arabidopsis through BASIC TRANSCRIPTION FACTOR 3 (BTF3) and BTF3-like (BTF3L) proteins (Ding et al., 2018b). Under cold stress conditions, OST1 phosphorylates BTF3L at the Ser50 residue. Phosphorylation of BTF3 and BTF3L facilitates the interaction of BTF3 and BTF3L with CBF proteins, thereby enhancing their stability. Additionally, BTF3 and BTF3L positively regulate $C B F$ gene expression, as the relative expression of $C B F$ genes was significantly increased in $B T F 3 L$ overexpression lines. Thirdly, OST1 interacts with a plasma membrane-localized clade-E GROWTH-regulating 2 (EGR2) phosphatase, thereby inhibiting the activity of OST1 under control temperatures (Ding et al., 2019). Under cold stress conditions, a myristoyl-switch on EGR2 leads to the cold activation of OST1, as the interaction between OST1 and
EGR2 is attenuated. Thus, EGR2 enhances the plant's ability to adapt to cold stress conditions (Ding et al., 2019).

\section{Regulation of cold acclimation by a MITOGEN ACTIVATED PROTEIN KINASE cascade}

MITOGEN-ACTIVATED PROTEIN KINASEs (MAPKs) have a critical role in cold signalling (Fig. 3) (Ramirez and Poppenberger, 2017). Interestingly, different MAPKs can function as either a positive or negative regulator of cold responsiveness by means of stabilizing or destabilizing proteins in the ICE1-CBF-COR pathway (Li et al., 2017; Ramirez and Poppenberger, 2017; Zhao et al., 2017). Two independent studies indicated that the MITOGEN-ACTIVATED PROTEIN KINASE KINASE 4 (MKK4)/MKK5-MPK3/ MPK6 cascade targets the ICE1 phospho-sites Ser94, Thr366, and Ser403. This leads to destabilization and subsequent degradation of the ICE1 protein and thus disruption of the freezing tolerance response. MPK3/4/6 themselves 


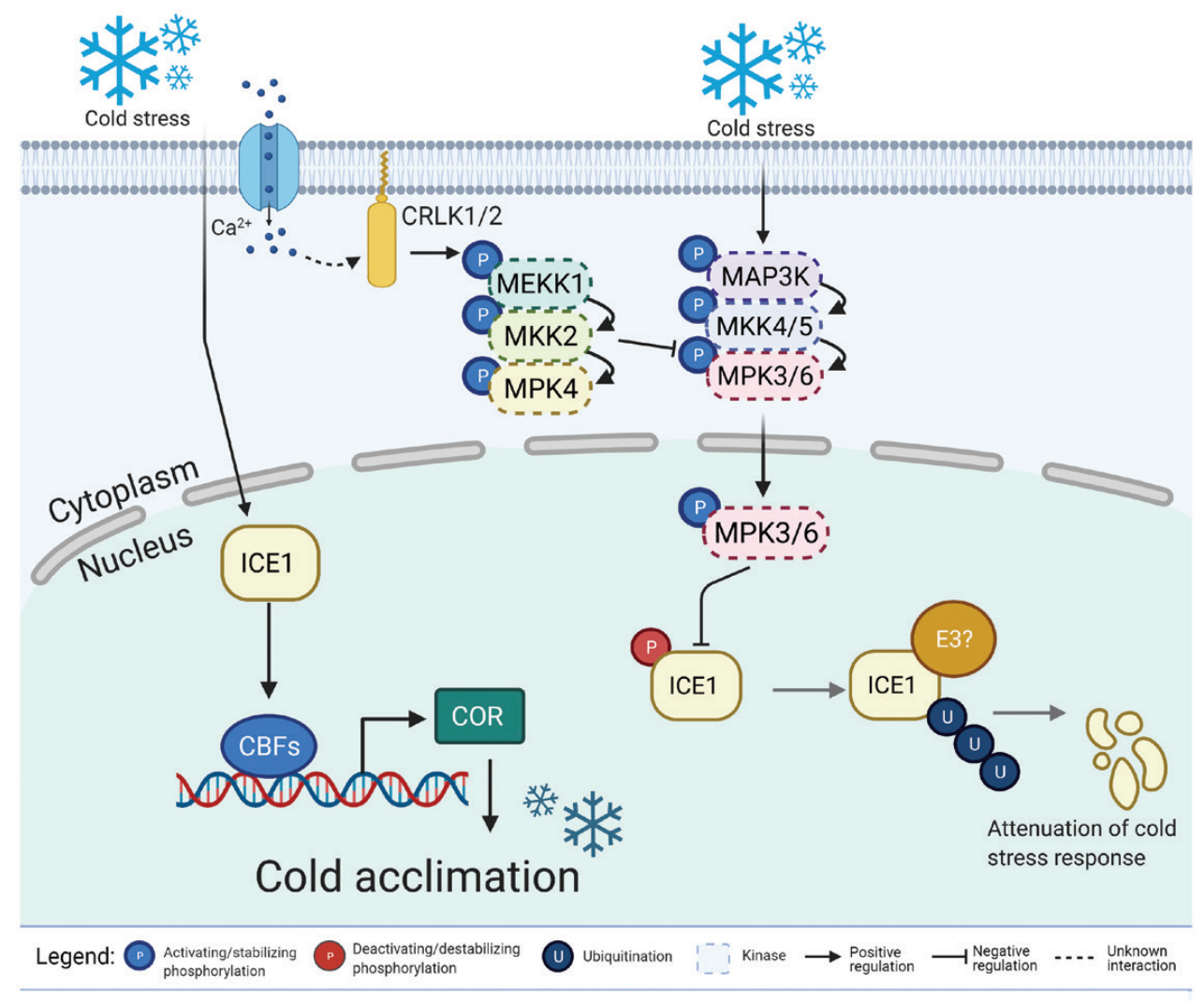

Fig. 3. Regulation of cold acclimation responses by MAPK-cascade signalling. Different MAP kinases function as either a positive or negative regulator of cold responsiveness by stabilizing or destabilizing proteins of the ICE1-CBF-COR pathway. The MKK4/5-MPK3/6 cascade phosphorylates ICE1 and thereby negatively regulates cold acclimation, by mediating destabilization and degradation of ICE1. MPK3/4/6 are rapidly activated by phosphorylation upon cold perception, which is proposedly mediated by MKK4/5. A cold stress-triggered calcium influx activates the plasma membrane-localized receptor-like kinases CRLK1/2. CRLK1 and CRLK2 then activate the MEKK1-MKK2-MPK4 cascade, which stimulates cold acclimation by repressing MPK3/6 activity. Symbols are explained at the bottom of the figure.

are rapidly activated by phosphorylation upon cold, which is proposedly mediated by MKK4/5 (Li et al., 2017; Zhao et al., 2017). Accordingly, $m p k 3$ and $m p k 6$ mutants display enhanced freezing tolerance and show increased expression of $C B F$ genes. In contrast, $m k k 1, m k k 2$, and $m p k 4$ mutants, in which MPK3 and MPK6 are constitutively active, display hypersensitivity to freezing and lower expression levels of CBF genes ( $\mathrm{Li}$ et al., 2017; Zhao et al., 2017).

During cold stress, the CALCIUM/calmodulin-regulated RECEPTOR-like KINASES 1 and 2 (CRLK1/2), which are present in the plasma membrane, are activated by a coldtriggered calcium influx. CRLK1 and CRLK2 then activate the MAP3K8-MKK2-MPK4 cascade, which positively regulates freezing tolerance by constitutively repressing MPK3/6 activity (Yang et al., 2020). It has been shown that MPK4 is activated by cold and is required for the cold stress response, as mpk 4 mutants are hypersensitive to freezing (Teige et al., 2004). CBF expression levels in the mpk4 mutants are significantly lower compared with wild type after $4{ }^{\circ} \mathrm{C}$ treatment. Additionally, the mpk4 mutant has increased levels of activated MPK3 and MPK6 (Zhao et al., 2017).
It is suggested that the negative regulation of ICE1 by MPK3/6 is important for balancing growth and acclimation responses to environmental conditions, as the over-stimulation of the $C B F$ regulon is detrimental for plant growth. The tight regulation of the MPK3/6-ICE1-CBF pathway could lead to rapid adjustments of the osmotic balance (disturbed in cold temperatures) and growth potential, thereby allowing plants to survive upon the onset of cold (growth suppression) on the one hand, and quickly recover after cold stress subsides (relieving growth suppression) on the other (Ramirez and Poppenberger, 2017). This acclimation/growth trade-off is likely also regulated by the brassinosteroid (BR) GSK3-like signalling kinase BRASSINOSTEROID-INSENSITIVE 2 (BIN2) (Fig. 2), as its kinase activity is inhibited during the early cold stress response (Ye et al., 2019). Under prolonged cold stress, BIN2 interacts with and phosphorylates ICE1 (Ye et al., 2019). This facilitates the interaction of ICE1 and the E2 ubiquitin ligase HOS1, resulting in ICE1 degradation.

Interestingly, tomato (Solanum lycopersicum) SIMPK1/2, a close homologue of Arabidopsis MPK6, mediates cold acclimation in this species ( $\mathrm{Lv}$ et al., 2017). An extensive 
phosphoproteome analysis revealed cold-induced phosphorylation of SNF1-RELATED PROTEIN KINASEs (SnRK2s) in a cold-tolerant cultivated tomato, which is possibly due to accumulation of ABA in the tested variety (Hsu et al., 2018). This suggests that SnRK2 activation by phosphorylation might be crucial for cold signalling. In contrast, a wild tomato species (Solanum pimpinellifolium) displayed phosphorylation of residues associated with MAPKs and of the tomato ICE1 homologue under cold stress, which appears to confer tolerance to this cold-sensitive variety (Hsu et al., 2018).

Moreover, a role for MAPK signalling was found in banana in a quantitative phosphoproteomics analysis between a cold sensitive Cavendish banana and relatively cold-tolerant Dajiao cultivar (both Musa spp.) in response to cold stress conditions (Gao et al., 2017). This suggests that elements of MAPK signalling of cold stress are conserved among dicots and monocots.

\section{Kinase regulation of thermomorphogenesis}

Warm ambient temperature perception, signalling, and the resulting growth acclimation responses such as hypocotyl elongation (thermomorphogenesis) show parallels with shade avoidance signalling pathways (Jung et al., 2016; Legris et al., 2016, 2017; Jin and Zhu, 2019). The photoreceptor phytochrome B (phyB) is a bona fide temperature sensor in plants (Legris et al., 2016; Jung et al., 2016) and functions in thermomorphogenesis by regulating the bHLH transcription factor PHYTOCHROME INTERACTING FACTOR 4 (PIF4), which is a central thermomorphogenesis signalling hub (Koini et al., 2009; Stavang et al., 2009). Recently it was shown that PIF7 also plays an important role in regulating daytime growth. It was found that translation of PIF7 mRNA - and thereby protein levels-is enhanced by high temperaturedependent relaxation of a PIF7 mRNA hairpin structure (Chung et al., 2020).

Warm temperature-dependent conversion of the active phyB Pfr to the inactive Pr conformation leads to nuclear exclusion of phyB and release of PIF4 inhibition. Thereafter, PIF4 initiates auxin biosynthesis, which subsequently triggers elongation growth (Franklin et al., 2011; Sun et al., 2012; van der Woude et al., 2019). In addition to auxin, BR plays an important role in thermomorphogenesis, as increased levels of $\mathrm{BR}$ are critical for diurnal and thermomorphogenic growth (Ibañez et al., 2018; Martínez et al., 2018).

Phytochromes thus play a major role in the regulation of PIFs and it is hypothesized that phytochromes, besides their autophosphorylation, also phosphorylate the PIF protein family. Photomorphogenesis research in Arabidopsis has shown that SUPPRESSOR OF PHYA-105 (SPA1), together with PhyB, can function as a kinase that phosphorylates PIF1 (Paik et al., 2019). Additionally, it was shown that in Avena sativa
PhyA (AsPhyA) can phosphorylate PIF1, PIF3, and PIF4 (Shin et al., 2016).

Phosphorylation marks PIF4 for proteasomal degradation (Bernardo-García et al., 2014). This phosphorylation is dynamic and light dependent, thereby affecting both the timing and the extent of hypocotyl elongation (Bernardo-García et al., 2014). PIF4 interaction with light-activated PhyB (Pfr) leads to the phosphorylation and degradation of the PIF4 protein (Lorrain et al., 2008). This, and cycling fluctuations in PIF4 mRNA levels, contributes to diurnal patterns of PIF4 protein abundance and thus growth. Interestingly, hyper-phosphorylated PIF4 accumulation is observed under warm ambient temperatures in both light and dark conditions, which stabilizes the protein (Fig. 4A) (Foreman et al., 2011). It has been suggested that this hyper-phosphorylation event occurs independent of photoreceptor activity.

The differential phosphorylation of PIF4 in light-dark cycles, and the effect of temperature thereon, is a case example of how protein phosphorylation can act as a switch: the light-induced phosphorylation of PIF4 destabilizes the protein (growth suppression), whereas in warm ambient temperatures the stable hyper-phosphorylated PIF4 form becomes dominant, thereby allowing elongation growth (thermomorphogenesis) (Foreman et al., 2011). PIF4 itself activates the transcription of a gene that encodes the PINOID protein kinase that regulates polarization of PIN-FORMED3 (PIN3), an auxin transporter, to the outer membranes of cells in the petiole (Park et al., 2019). This contributes to leaf cooling in higher ambient temperatures.

PIF4 is also a known phosphorylation target of the GSK3like kinase BIN2 and brassinosteroid signalling mutants exhibit defects in thermomorphogenesis responses (Fig. 4A) (Bernardo-García et al., 2014; Ibañez et al., 2018). Interestingly, the functioning of both PIF4 and auxin depends on BR (Ibañez et al., 2018). Perception of BR leads to the formation of BRASSINOSTEROID INSENSITIVE 1 (BRI1)BRASSINOSTEROIDS INSENSITIVE 1-ASSOCIATED RECEPTOR KINASE 1 (BAK1) heterodimers (Li and Nam, 2002; Russinova et al., 2004). This initiates a phosphorylation cascade that promotes the activation and stability of BRASSINAZOLE RESISTANT 1 (BZR1) and BRI-EMSSUPPRESSOR 1 (BES1) (Fig. 4B top panel) (Wang et al., 2002; Yin et al., 2002).

In the absence of BR, BZR1 and BES1 are phosphorylated by BIN2, leading to their inactivation and degradation (Fig.4B bottom panel) (Li and Nam, 2002; Peng et al., 2008). BIN2 itself is dephosphorylated by the phosphatase BRI1-SUPRESSOR1 (BSU1), leading to BIN2 degradation (Peng et al., 2008; Kim et al., 2009). BSU1 thereby prevents BIN2-mediated phosphorylation of BZR1 and BES1. BZR1 accumulates in the nucleus upon exposure to high ambient temperatures, where it binds to the promoter of PIF4 inducing PIF4 expression (Ibañez et al., 2018). BES1 can form homodimers that bind to BR biosynthesis promoters and inhibit their expression during daytime. In warm temperatures 


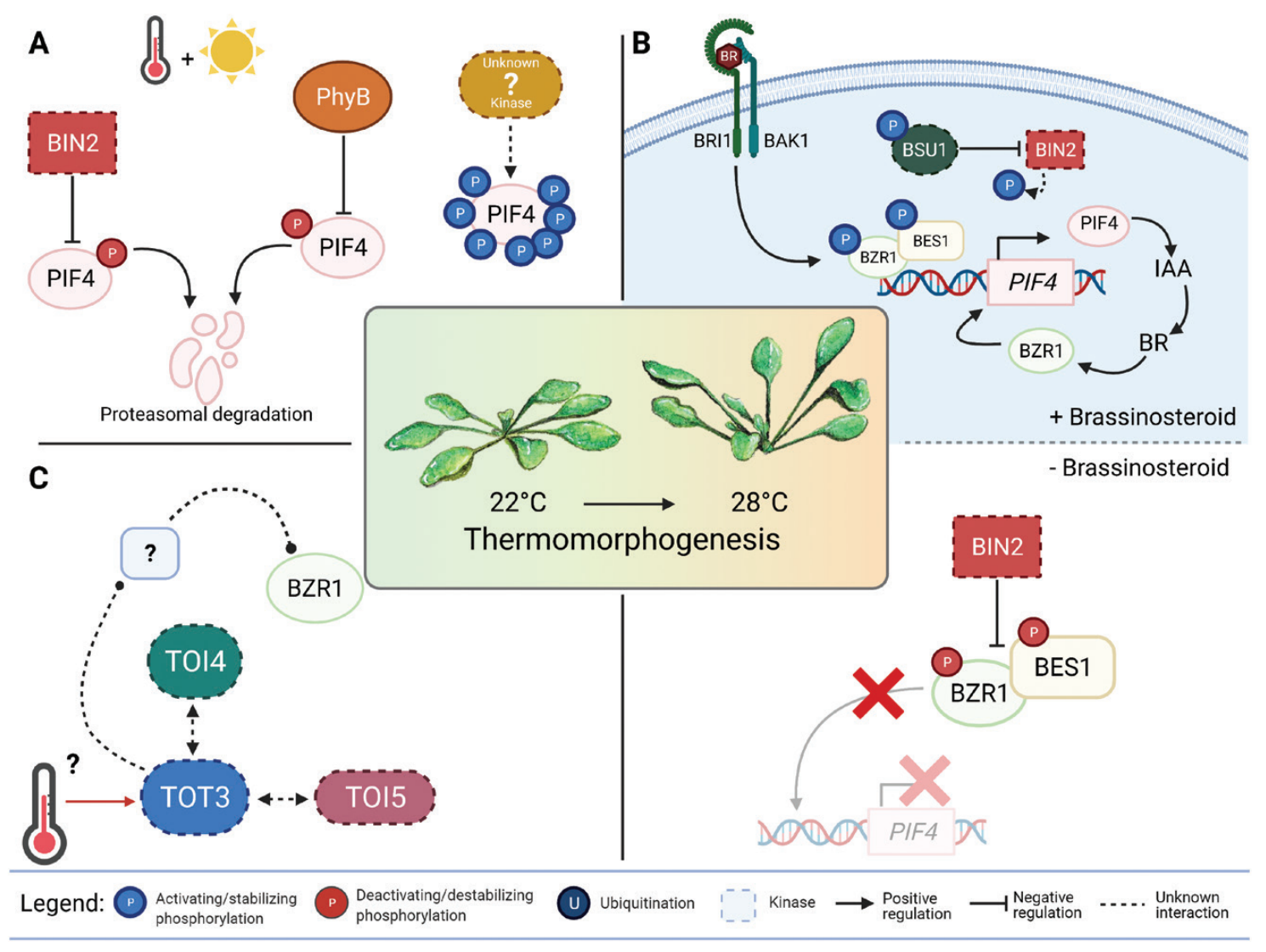

Fig. 4. Thermomorphogenesis is regulated by kinases on multiple levels. The central panel of the figure schematically visualizes thermomorphogenesis of Arabidopsis during vegetative growth. In response to warm ambient temperatures, the plant exhibits elongated petioles and hyponastic growth. This leads to an open rosette structure that aids the plant's cooling capacity. (A) PIF4 plays a key role in thermomorphogenesis and its stability is regulated by phosphorylation. PIF4 is phosphorylated by BIN2 in a light-dependent manner, leading to its degradation. PIF4 interaction with light-activated PhyB leads to phosphorylation and degradation of PIF4. In both light and dark, warm ambient temperatures trigger an increase of stable hyper-phosphorylated PIF4. The kinase responsible for this is unknown. (B) Thermomorphogenesis is brassinosteroid (BR)-dependent. Top panel: in the presence of BR, BRI1/ BAK1 heterodimers are formed. This leads to a phosphorylation cascade that phosphorylates, and thereby stabilizes, BZR1-BES1. BZR1-BES1 in turn promote the transcriptional activity of PIF4, thereby enhancing thermomorphogenesis. In the presence of BR, the phosphatase BSU1 is activated by phosphorylation. BSU1 dephosphorylates BIN2, leading to its degradation. Lower panel: in the absence of BR, phosphatase BSU1 is not activated, thereby relieving the repressive effect on BIN2. BIN2 can therefore phosphorylate BZR1 and BES1, which prohibits their binding to the promotor of PIF4. (C) The MAP4K TARGET OF TEMPERATURE 3 (TOT3) is localized at the plasma membrane and phosphorylated TOT3 is more abundant under warm temperature. TOT3 functions independent of PIF4 and phyB thermo-signalling and light signalling pathways and likely controls BR-mediated hypocotyl elongation under warm temperatures by regulating BZR1 activity. TOT3 interacts with related MAP4Ks, TOT3-INTERACTING PROTEIN 4 (TOI4), and TOI5, which redundantly regulate warm temperature-mediated growth and/or are (in)direct targets of TOT3. Symbols are explained at the bottom of the figure.

PIF4 accumulates and can interact with BES1 (Koini et al., 2009; Martínez et al., 2018). Consequently, BES1 activity switches from a repressive to transcription-activating modus, which triggers $\mathrm{BR}$ accumulation.

Furthermore, the DE-ETIOLATED1 (DET1)CONSTITUTIVE PHOTOMORPHOGENIC 1 (COP1)ELONGATED HYPOCOTYL 5 (HY5) regulon modulates both plant photomorphogenesis and thermomorphogenesis in a BIN2-dependent manner (Delker et al., 2014). HY5 is a negative regulator of elongation growth (Delker et al., 2014). Warm temperature triggers nuclear localization of COP1, where it gates the degradation of HY5 (Park et al., 2017). This relieves the repression of elongation growth, allowing hypocotyl elongation.
Recently, photomorphogenesis research showed that the activity of the BIN2 kinase is enhanced by HY5. The physical interaction of HY5 with BIN2 represses hypocotyl elongation, likely by enhancement of BIN2 Tyr200 autophosphorylation, suppressing accumulation of the transcription factor BZR1 (Li et al., 2020). HY5 is also known to be phosphorylated by SPA proteins (Wang et al., 2021). Unphosphorylated HY5 interacts with both COP1 and SPA1, leading to its degradation. Once phosphorylated by SPA proteins, HY 5 becomes stable in the dark. The COP1SPA complex functions as an E3 ubiquitin ligase complex, but SPA proteins can also function as protein kinases (Wang et al., 2021), which is due to an N-terminal Ser/Thr kinase domain in the SPA proteins (Wang et al., 2021). 
Some of the kinases mentioned here have not been directly linked to thermomorphogenesis, but the published data suggest that these and other kinases, and phosphatases alike, could very well have a critical role in plant adaptation to increased ambient temperatures, which should be investigated further.Taken together, the role of protein kinases in thermomorphogenesis remains a fruitful field of study.

\section{Thermo-signalling by the MAP4K kinase TOT3/MAP4K4K}

Recently, a functionally conserved warm temperature signalling complex of MITOGEN-ACTIVATED PROTEIN KINASE KINASE KINASE KINASEs (MAP4Ks) was shown to play a role in warm temperature-mediated growth regulation (Vu et al., 2021) (Fig. 4C). MAP4K TAR GET OF TEMPERATURE 3 (TOT3) is localized at the plasma membrane and the phosphorylated TOT3 is more abundant under warm temperature. While temperature perception at the plasma membrane is found in many organisms, including (cyano)bacteria (Los and Murata, 2004; Inda et al., 2014), such a temperature sensing mechanism was lacking in plants. An Arabidopsis tot 3 mutant is less responsive to warm temperature with respect to hypocotyl elongation, but responds to some other hypocotyl growthpromoting cues. Furthermore, TOT3 functions independent of PIF4 and phyB thermo signalling and light signalling pathways, but does likely control brassinosteroid-mediated hypocotyl elongation under warm temperatures by regulating BZR 1 activity. Interestingly, wheat TOT3 is also important for growth promotion at elevated temperatures, indicating that TOT3 function is conserved in dicots and monocots. Finally, TOT3 interacts with related MAP4Ks, TOT3-INTERACTING PROTEIN 4 (TOI4) and TOI5, which redundantly regulate warm temperature-mediated growth and/or are (in)direct targets of TOT3. This novel pathway emphasizes the importance of phosphorylation during thermomorphogenesis and adds another signalling cascade to the regulation of this process.

\section{Kinase regulation of heat stress}

Plants are considered to experience heat stress or heat shock when temperature surpasses a temperature threshold level for a certain duration, resulting in irreversible damage to plant performance (growth, reproduction, etc.) and/or results in plant death (Wahid et al., 2007; Zhu et al., 2021). Roughly, an increase of more than $10^{\circ} \mathrm{C}$ above the optimal temperature is deemed heat stress, although this depends on the species studied. For some crop species, heat stress is experienced at temperatures higher than $30^{\circ} \mathrm{C}$ (Wahid et al., 2007). For Arabidopsis, exposure to a sudden heat shock of around $40{ }^{\circ} \mathrm{C}$ will often lead to plant death (Yeh et al., 2012). However, acquired thermotolerance can be induced when the plant is preexposed to moderate sub-lethal heat stress $<37{ }^{\circ} \mathrm{C}$, thereby increasing the chances of surviving a subsequent more severe heat shock (Yeh et al., 2012; Larkindale andVierling, 2008; Ling et al., 2018).

At the molecular level, heat stress damages cellular components through mechanisms such as membrane fluidization and protein denaturation. Additionally, heat stress induces the accumulation of reactive oxygen species (ROS) that cause malfunctioning of organelles (Kotak et al., 2007; Wahid et al., 2007). The obtained cellular damage is often a direct physical consequence of heat stress and can act as a signal triggering heat stress responses (Ohama et al., 2017). For instance, recently it was demonstrated that the activation of protein kinase BIN2 is mediated by ROS signalling that results from cellular damage (Song et al., 2019). Such BIN2 activation has not yet been studied in the context of heat stress but it seems likely that ROS-mediated BIN2 activation also plays a role in heat stress signalling and has an impact on plant tolerance.

At the molecular level, heat stress responses are governed by HEAT SHOCK TRANSCRIPTION FACTORs (HSFs), a protein family that is highly conserved among eukaryotes (Schlesinger, 1990; Nover et al., 2001). HSFs are maintained in an inactive state until the onset of heat stress (Wu, 1995 and associate with heat shock proteins (HSP) in cells that are not heat stressed. When heat occurs, HSPs function as chaperones and are recruited to heat-damaged proteins. The dissociation of the HSP-HSF dimer releases the HSF, and subsequently the monomeric HSFs trimerize to form active homotrimers that can bind to cis elements in the promoters of HSP genes, known as Heat Shock Elements (HSEs) (Wu, 1995). Binding of homotrimerized HSFs to HSEs leads to the production of functional heat shock proteins (HSPs). These HSPs not only restore the function of denatured proteins after heat stress and prevent further damage, but also assist in degradation of proteins when they are misfolded beyond repair (Izumi, 2019; McLoughlin et al., 2019). In addition, because of the massive increase in HSPs in heat-stressed cells, the HSP-HSF heterodimer balance is restored, thereby dampening the heat shock response.

(De)phosphorylation of HSPs and HSFs shapes the heat stress response (Reindl et al., 1997; Liu et al., 2008). Members of the HEAT SHOCK TRANSCRIPTION FACTOR A1 family (HsfA1s) are considered to play an important role in the heat stress response as 'master regulators' (Mishra et al., 2002; Yoshida et al., 2011). HSF1 is phosphorylated by at least two kinases. First, the cyclin-dependent kinase CDC2a phosphorylates HSF1 and thereby inhibits binding of HSF1 to HSEs (Fig. 5A) (Reindl et al., 1997). HSF1 can also be activated by phosphorylation and promote HSP gene expression. Liu and colleagues demonstrated that CaM-BINDING PROTEIN KINASE 3 (CBK3)-mediated phosphorylation of HSFA1a promotes HSF1 binding to HSEs in the downstream heat stress signal transduction pathway (Fig. 5A) (Liu et al., 2008).

HsfA1s directly regulate expression of transcription factors that are important in the heat stress response, including the induction of DEHYDRATION-RESPONSIVE ELEMENT 


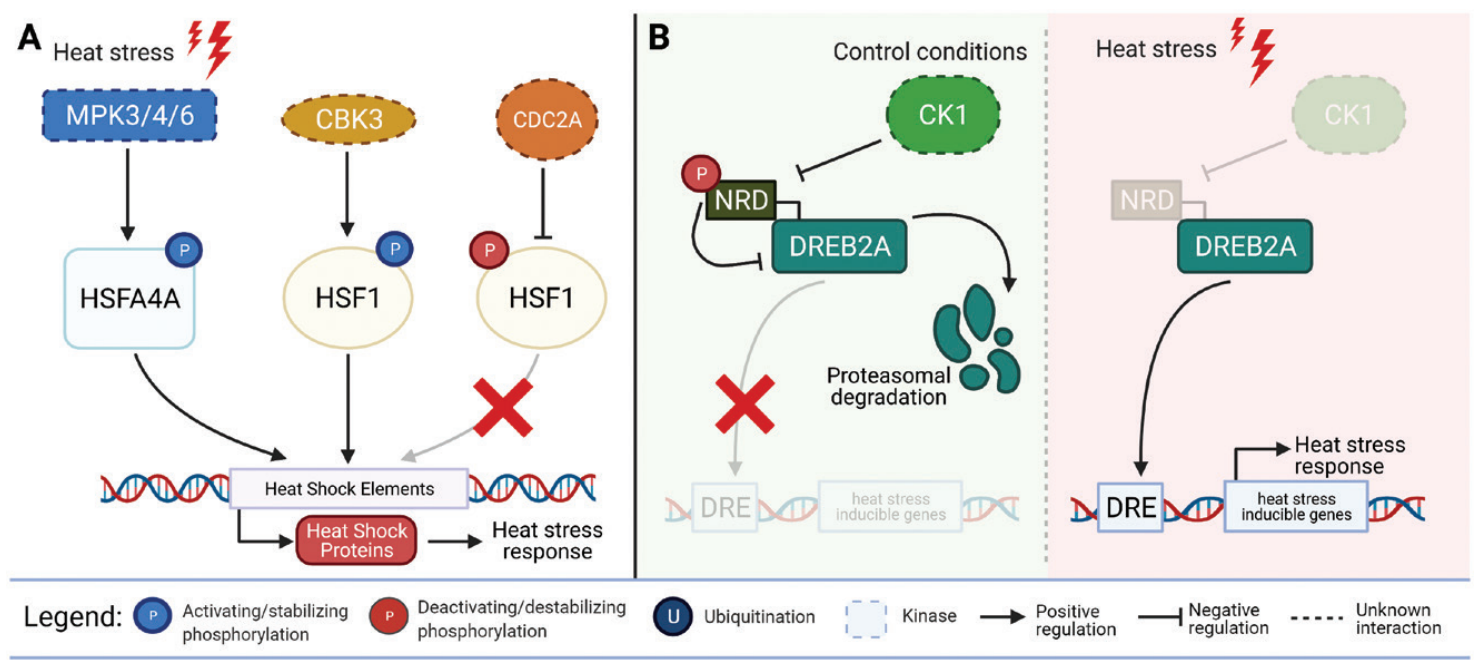

Fig. 5. Kinase regulation of heat stress responses. (A) During heat stress, phosphorylation of HSFA4A by MPK3/4/6 modulates the induction of target genes, thereby enhancing the heat stress response. HSF1 is phosphorylated by at least two kinases. CDC2a negatively regulates the heat stress response by phosphorylating HSF1 and thereby inhibits DNA binding of HSF1 to HSES whereas HSF1 is also activated by phosphorylation. CaM-BINDING PROTEIN KINASE 3 (CBK3)-mediated phosphorylation of HSFA1a positively regulates the heat stress response by enhancing HSF1 binding to HSEs in the downstream heat stress signal transduction pathway. (B) DREB2A is a transcriptional activator that plays a critical role in the heat stress response. Stabilization of the protein ensures transcriptional activation of downstream stress-inducible genes. Ser/Thr residues in the integral negative regulatory domain (NRD) of DREB2A are phosphorylated in control temperature conditions. This phosphorylation is most likely mediated by CASEIN KINASE 1 (CK1). During heat stress conditions phosphorylation of the NRD is inhibited, which allows for stabilization and activation of DREB2A. This enhances thermotolerance by allowing DREB2A binding to DRE elements in heat stress-inducible genes. Symbols are explained at the bottom of the figure.

BINDING PROTEIN 2A (DREB2A) (Yoshida et al., 2011). DREB2A is a transcriptional activator and both HsfA1 and DREB2a play a critical role in the heat stress response, as expression of many heat shock protein genes, including HSP70, is HsfA1/DREB2A-dependent (Sakuma et al., 2006). Additional stabilization of DREB2A is necessary to ensure transcriptional activation of downstream stress-inducible genes. The integral negative regulatory domain is important for stabilization of DREB2a (Morimoto et al., 2017). Ser/Thr residues in the negative regulatory domain of DREB2A are phosphorylated in control temperature conditions (Mizoi et al., 2019) (Fig. 5B). This phosphorylation is most likely mediated by CASEIN KINASE 1 (CK1) (Mizoi et al., 2019). Such phosphorylation of the negative regulatory domain is important for the proteasomal degradation of DREB2A. Heat stress conditions inhibit the phosphorylation of the NRD allowing for the stabilization and activation of DREB2A, resulting in enhanced thermotolerance (Fig. 5B) (Mizoi et al., 2019). In addition to the HSFA1 family, Arabidopsis induction of HSFA $4 A$ expression and a rise in HSFA4A protein levels are observed during heat stress $\left(37^{\circ} \mathrm{C}\right)$ (Pérez-Salamó et al., 2014; Andrási et al., 2019). Recent research suggests that HSFA4A is phosphorylated by MPK3, MPK6, and MPK4 (Fig. 5A). The dominant HSFA4A MAPK phosphorylation site is Ser309. HSFA4A binds to the promoters of the small heat shock protein HSP17.6A, transcription factors WRKY30, and the zinc finger protein ZAT12. Phosphorylation of HSFA4A by MPK3/4/6 modulates its activity and leads to the induction of target genes (Andrási et al., 2019).

\section{MITOGEN ACTIVATED PROTEIN KINASE signalling during heat stress}

Guard cell expansion results in opening of stomatal pores, which contributes to enhanced leaf cooling under heat stress. Recently, it was shown that phototropin-mediated phosphorylation of the MAP4K BLUE LIGHT SIGNALING1 (BLUS1) regulates stomatal opening by activating $\mathrm{H}^{+}$-ATPases, in conjunction with 14-3-3 proteins (Fig. 6A) (Kostaki et al., 2020). The ability of phototropins to perceive temperature is based on the lifetime of the photoactivated state of phototropins (Fujii et al., 2017). Thus, stomatal opening depends on integration of both light and high temperature signals (Kostaki et al., 2020).

MAPK signalling, and in particular the YODA-MPK3/6SPEECHLESS signalling pathway, also promotes production of guard cells under heat stress conditions and this signalling cascade is relatively well understood. During acute heat stress, the transcription factor SPEECHLESS (SPCH), a positive regulator in the initiation of the stomatal cell lineage, is deactivated due to phosphorylation by the YODA-HSP90 module (Fig. 6B) (Gray, 2007). Under both control and heat stress conditions HSP90s interact with YODA, thereby modulating the phosphorylation of downstream targets such as MPK6 and SPCH. This HSP90-YODA interaction eventually results in HSP90-mediated regulation of stomatal development, thereby contributing to heat stress by suppressing SPCH-dependent stomatal development, which is suggested as an adaptive heat stress response mechanism (Samakovli et al., 2020). In addition, the conserved PROTEIN PHOSPHATASE 2As (PP2As) 

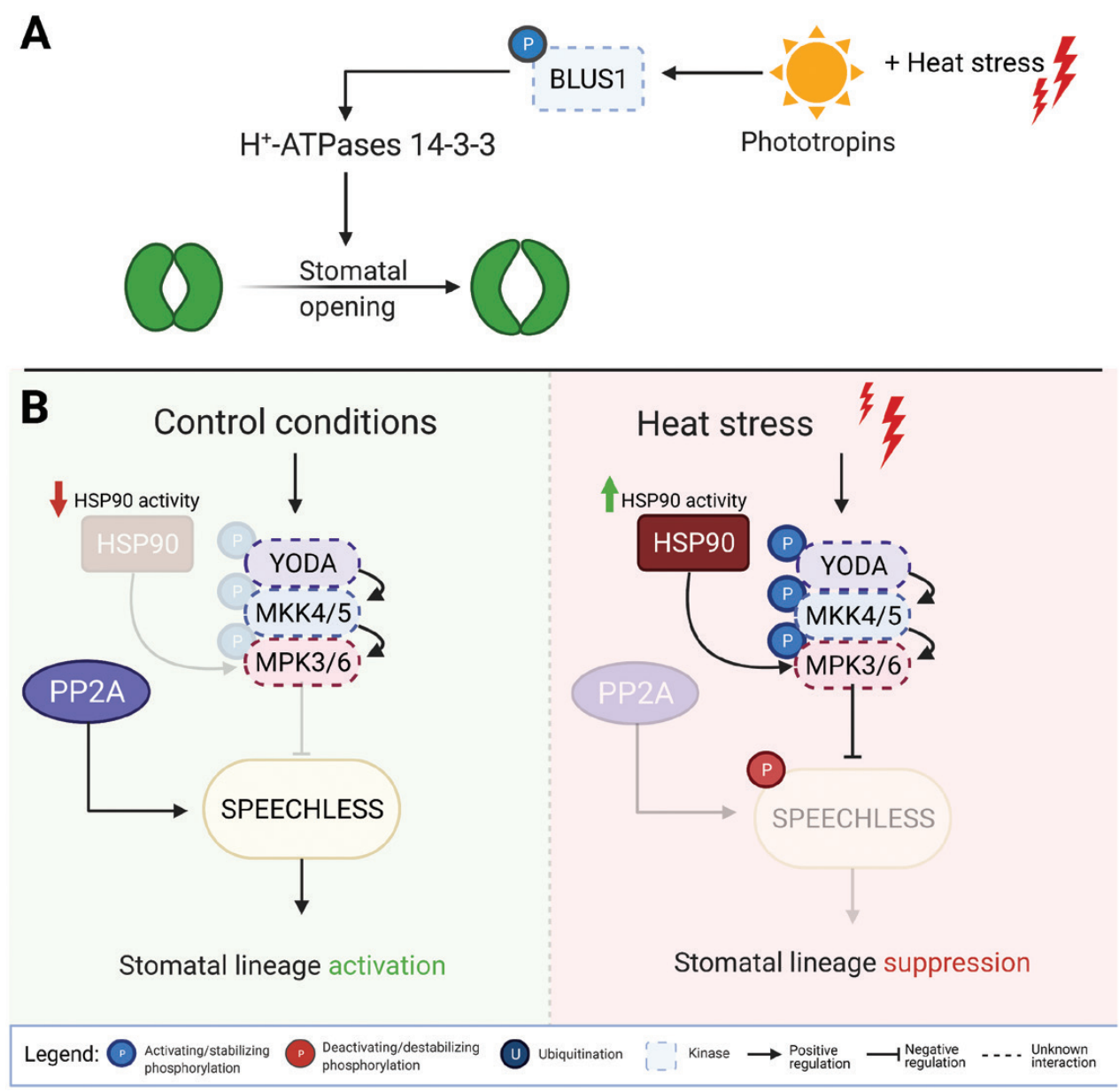

Fig. 6. Kinase activity regulates stomatal opening and stomatal development during heat stress. (A) Phototropin-mediated phosphorylation of BLUE LIGHT SIGNALING1 (BLUS1) in the light during heat stress drives stomatal opening by activating $\mathrm{H}^{+}$-ATPases that promote stomatal opening in conjunction with 14-3-3 proteins. (B) During acute heat stress, SPEECHLESS (SPCH) is phosphorylated and deactivated by the YODA-HSP90 module. HSP90s interact with YODA and modulate the phosphorylation of downstream targets, such as MPK6 and SPCH, under control and heat stress conditions. This leads to HSP90-mediated negative regulation of stomatal development. In control temperatures, PROTEIN PHOSPHATASE 2As (PP2As) positively regulates stomatal development by enhancing the stability of SPCH protein. Symbols are explained at the bottom of the figure.

contribute to stomatal development by enhancing the stability of $\mathrm{SPCH}$ protein in control temperature conditions (Bian et al., 2020).

MAPKs are important for the heat stress response in tomato as well. A recent study demonstrated that tomato SIMPK1, the close homologue of Arabidopsis MPK6, is a negative regulator of the heat stress response (Ding et al., 2018b), as its overexpression resulted in reduced tolerance to heat stress. The authors propose that SIMPK1 is involved in modulating membrane lipid peroxidation and antioxidant enzyme activities. For this, SIMPK1 interacts with a serine-proline-rich protein homologue (SISPRH1) (Ding et al., 2018a). By expressing SISPRH1 in Arabidopsis, thermotolerance and antioxidant capacity were indeed reduced (Ding et al., 2018b). Tomato thermotolerance is also enhanced by calcium-dependent protein kinases (CPKs) (Hu et al., 2021). CPK28 phosphorylates ascorbate peroxidase (APX), an antioxidant enzyme that, if mutated, leads to heat sensitive tomato plants (Hu et al., 2021).

\section{ERECTA kinase signalling in cold and warm temperature responses}

The leucine-rich repeat receptor-like protein kinase ERECTA likely functions in multiple temperature signalling networks. ERECTA, which contains extracellular leucine-rich repeats, localizes to the plasma membrane (Torii et al., 1996). An analysis of natural variation suggests that ERECTA is involved in temperature-dependent shade avoidance (Patel et al., 2013). Arabidopsis Landsberg erecta plants treated with a reduced ratio of red-to-far red light (a mimic of canopy shade) at low temperatures $\left(16^{\circ} \mathrm{C}\right)$ showed reduced petiole elongation and leaf hyponastic responses compared with control conditions. Interestingly, the phenotype was accompanied by increased leaf thickness, increased biomass, increased soluble sugars and an altered metabolite profile (Patel et al., 2013). These are all characteristic of cold acclimation. On the other hand, the ERECTA family (ER, ERECTA-LIKE1 (ERL1) and ERL2) plays a role 
in cell elongation in Arabidopsis hypocotyls by activating auxin biosynthesis (Qu et al., 2017; Du et al., 2018; Jin and Zhu, 2019), which resembles thermomorphogenesis. Although not directly studied in a warm temperature context yet, ERECTA regulates the PACLOBUTRAZOL RESISTANCE1 (PRE1) gene family by genetic interaction with the ATP-dependent chromatin remodelling complex SWR1, which contains the conserved Swi2/Snf2-related ATPase Swr1p (Kobor et al., 2004; Cai et al., 2017). Subsequently the SWR1 complex incorporates the H2A.Z histone variant into the nucleosomes of all members of the PRE1 gene family, and H2A.Z levels knowingly mediate thermo-signalling responses in Arabidopsis (Kumar and Wigge, 2010).

Gene Ontology (GO) analysis of expression quantitative trait locus data indicated that pathways potentially regulated by ERECTA are enriched for the GO term 'response to heat', and ERECTA has been shown to function upstream of the MAPK cascade composed of YODA-MKK4/MKK-MPK3/MPK6 (van Zanten et al., 2009a; Meng et al., 2013). The MPK3/ MPK6 module itself is also involved in heat stress signalling and regulation of cold acclimation (Li et al., 2017; Zhao et al., 2017; Samakovli et al., 2020). Finally, heterologous overexpression of Arabidopsis ERECTA improves the thermotolerance of both rice and tomato (Shen et al., 2015). In accordance, a loss-offunction mutation of a rice $E R$ homologue, as well as reduced expression of a tomato $E R$ allele, lowered the thermotolerance of the respective species when exposed to heat stress (Shen et al., 2015). The exact roles of ERECTA remains to be elucidated, but ERECTA is seemingly an important regulator of temperature signalling network(s) leading to temperature tolerance and acclimation.

\section{Discussion and outlook}

The importance of kinases and phosphatases in mediating plant temperature tolerance and acclimation is irrefutable. Until recently, however, kinases, phosphatases, and PTMs in general have been somewhat neglected in studies on mild high temperature signalling cascades and thermomorphogenesis, contrasting with studies of transcriptional and (epi)genetic and hormonal regulation (reviewed in Chinnusamy et al., 2010; Eremina et al., 2016; Quint et al., 2016; Casal and Balasubramanian, 2019; Hu et al., 2020).

Interestingly, in the Arabidopsis $p h y$-abcde quintuple null mutant, up to $21 \%$ of the warm temperature-regulated transcriptome is not deregulated (Jung et al., 2016). Therefore, novel temperature signalling pathways remain to be discovered and these could very well involve kinase- and phosphatase-mediated signalling ( $\mathrm{Vu}$ et al., 2019), which is recently confirmed by reports on warm temperature-mediated phosphorylation in Arabidopsis, wheat, and soybean, and the discovery of TOT3 as a temperature-specific regulator of thermomorphogenesis in Arabidopsis and wheat (Vu et al., 2018b, 2021). In line with this, it is hypothesized that a putative CDC-Like Kinase (CLK) could act as a thermosensor in human cells (Lin et al., 2020). In this study, CLKs were shown to be required for temperatureresponsive alternative splicing (Haltenhof et al., 2020). CLKs are highly conserved, and three homologues are known in Arabidopsis (Lin et al., 2020). It would be of interest to test for a similar role of CLKs in temperature perception and acclimation in planta as well.

As presented in this review, heat stress responses, cold acclimation, and thermomorphogenesis are increasingly well understood. Nevertheless, these processes have been mainly studied in specific conditions and focus should be laid on interconnecting the different research areas. Several kinases function in a broad range of temperatures in different key pathways required for temperature acclimation and tolerance. We therefore advocate including temperature gradients in temperature research practice, instead of approaching temperature regimes in a binary fashion (i.e. temperature treatment versus control), especially when it comes to the study of the role of PTMs in the molecular networks contributing to temperature signalling and responses. In the above, kinases have been described with a (putative) role in both cold and high temperature signalling. For instance, BIN2 fine-tunes the early cold acclimation response by phosphorylating ICE1, whereas in response to light, PhyB induces BIN2-mediated phosphorylation and degradation of PIF4, which may link BIN2 to warm temperature signalling (Lorrain et al., 2008; Foreman et al., 2011; BernardoGarcía et al., 2014; Ye et al., 2019). Additionally, ERECTA kinase signalling in cold and warm temperature signalling remains to be elucidated.

It is unknown how exactly kinases and phosphatases alike function over a range of temperatures to (de)phosphorylate various targets. However, some kinases, including MPK6, exhibit broad target promiscuity and control different biological processes by (differential) phosphorylation of various protein substrates and sites (Xu and Zhang, 2015). Possibly, temperature-specific signalling by kinases could be determined by their protein targets. Different substrates, such as ICE1, are phosphorylated by various kinases at different residues and the resulting phosphocode determines the function of the protein in the current cellular context. Such combinatorial inputs from diverse kinases and phosphatases could be key to control the overall signalling output upon a (temperature) cue. Mapping and understanding this phosphocode for each phosphoprotein in different temperature environments is therefore essential for comprehensively understanding the myriad cellular activities and responses to temperature. So far, most kinases known to have a function in thermo-signalling function in other signalling processes as well. It remains to be seen if there are kinases or phosphatases that have a temperature-specific function and perhaps even can fulfil a direct thermosensory role. These would be prime targets for biotechnological applications, as this would increase specificity and reduce off-target 
activities. In this sense, TOT3 is an interesting candidate, as this kinase regulates temperature acclimation without interfering with light quality signalling and so far has not been linked to signalling networks other than high ambient temperature signalling ( $\mathrm{Vu}$ et al., 2021).

Kinases might have different targets at different temperatures, and thereby function in multiple temperature signalling pathways. Detecting such temperature-dependent target switching could help in understanding how plants balance growth versus temperature tolerance/acclimation, and these targets could be interesting for breeding thermotolerant crops as well. In tomato, S1HY 5 integrates both internal and external cues such as light, temperature, and responsiveness to hormones to balance plant growth and cold tolerance (Wang et al., 2019). Recently it was shown that C-REPEAT BINDING FACTOR1 (CBF1), which plays a central role in plant cold acclimation, promotes hypocotyl elongation at ambient temperatures in Arabidopsis (Dong et al., 2020). Additionally, COLD-REGULATED GENE 27 (COR27), which also plays a role in cold acclimation, regulates hypocotyl elongation by controlling the activity of HY5 and promoting PIF4 expression by binding to its promoter (Zhu et al., 2020).

Most studies on plant responses to changing temperature have been performed in model plant species such as Arabidopsis and tomato. Such knowledge on temperature signalling components must be translated to (other) crops to facilitate breeding efforts towards the development of thermotolerant crop varieties. It is helpful in this respect that thermomorphogenesis, cold acclimation, and heat stress responses are relatively well-conserved among different crop species (Quint et al., 2016; Fahad et al., 2017; Shi et al., 2018; Jacott and Boden, 2020). Sensitive methods and workflows already allow for accurate observations of the (phospho) proteome of crops including maize, wheat, tomato, and banana and are publicly available (Vu et al., 2016, 2018b; Gao et al., 2017; Hsu et al., 2018). Knowledge generated using such workflows could prove instrumental in the development of thermotolerant crop varieties that can mitigate or tolerate suboptimal or stressful temperatures, perhaps even by surpassing validation in Arabidopsis.

\section{Acknowledgements}

We would like to thank Prof. Sjef Smeekens (Utrecht University) for critically reading the manuscript. Figures were created with BioRender.com.

\section{Funding}

This work is supported by Graduate School Green Top Sectors grant GSGT.2018.007 of the Netherlands Organization for Scientific Research (NWO) to MP and MvZ. IDS acknowledges support from the Research Foundation-Flanders (FWO.OPR.2019.0009.01).

\section{References}

Andrási N, Rigó G, Zsigmond L, et al. 2019. The mitogen-activated protein kinase 4-phosphorylated heat shock factor A4A regulates responses to combined salt and heat stresses. Journal of Experimental Botany $\mathbf{7 0}$, 4903-4918.

Arsova B, Watt M, Usadel B. 2018. Monitoring of plant protein posttranslational modifications using targeted proteomics. Frontiers in Plant Science 9, 1168.

Barnes AC, Benning C, Roston RL. 2016. Chloroplast membrane remodeling during freezing stress is accompanied by cytoplasmic acidification activating SENSITIVE TO FREEZING2. Plant Physiology 171, 2140-2149.

Barrero-Gil J, Salinas J. 2017. CBFs at the crossroads of plant hormone signaling in cold stress response. Molecular Plant 10, 542-544.

Battisti DS, Naylor RL. 2009. Historical warnings of future food insecurity with unprecedented seasonal heat. Science 323, 240-244.

Bernardo-García S, de Lucas M, Martínez C, Espinosa-Ruiz A, Davière JM, Prat S. 2014. BR-dependent phosphorylation modulates PIF4 transcriptional activity and shapes diurnal hypocotyl growth. Genes \& Development 28, 1681-1694.

Bhaskara GB, Wong MM, Verslues PE. 2019. The flip side of phosphosignalling: regulation of protein dephosphorylation and the protein phosphatase 2Cs. Plant, Cell \& Environment 42, 2913-2930.

Bian C, Guo X, Zhang Y, Wang L, Xu T, DeLong A, Dong J. 2020. Protein phosphatase $2 \mathrm{~A}$ promotes stomatal development by stabilizing SPEECHLESS in Arabidopsis. Proceedings of the National Academy of Sciences, USA 117, 13127-13137.

Bridge LJ, Franklin KA, Homer ME. 2013. Impact of plant shoot architecture on leaf cooling: a coupled heat and mass transfer model. Journal of the Royal Society, Interface 10, 20130326.

Cai H, Zhao L, Wang L, Zhang M, Su Z, Cheng Y, Zhao H, Qin Y. 2017. ERECTA signaling controls Arabidopsis inflorescence architecture through chromatin-mediated activation of PRE1 expression. New Phytologist $\mathbf{2 1 4}$ 1579-1596.

Casal JJ, Balasubramanian S. 2019. Thermomorphogenesis. Annual Review of Plant Biology 70, 321-346.

Challinor AJ, Watson J, Lobell DB, Howden SM, Smith DR, Chhetri N. 2014. A meta-analysis of crop yield under climate change and adaptation. Nature Climate Change 4, 287-291.

Chinnusamy V, Ohta M, Kanrar S, Lee BH, Hong X, Agarwal M, Zhu JK. 2003. ICE1: a regulator of cold-induced transcriptome and freezing tolerance in Arabidopsis. Genes \& Development 17, 1043-1054.

Chinnusamy V, Zhu J, Zhu JK. 2007. Cold stress regulation of gene expression in plants. Trends in Plant Science 12, 444-451.

Chinnusamy V, Zhu JK, Sunkar R. 2010. Gene regulation during cold stress acclimation in plants. Methods in Molecular Biology 639, 39-55.

Chung BYW, Balcerowicz M, Di Antonio M, Jaeger KE, Geng F, Franaszek K, Marriott P, Brierley I, Firth AE, Wigge PA. 2020. An RNA thermoswitch regulates daytime growth in Arabidopsis. Nature Plants 6, 522-532.

Craufurd PQ, Wheeler TR. 2009. Climate change and the flowering time of annual crops. Journal of Experimental Botany 60, 2529-2539.

Crawford AJ, McLachlan DH, Hetherington AM, Franklin KA. 2012. High temperature exposure increases plant cooling capacity. Current Biology 22, R396-R397.

Delker C, Sonntag L, James GV, et al. 2014. The DET1-COP1-HY5 pathway constitutes a multipurpose signaling module regulating plant photomorphogenesis and thermomorphogenesis. Cell Reports 9, 1983-1989.

Ding H, He J, Wu Y, Wu X, Ge C, Wang Y, Zhong S, Peiter E, Liang J, $\mathbf{X u} \mathbf{W}$. 2018a. The tomato mitogen-activated protein kinase SIMPK1 is as a negative regulator of the high-temperature stress response. Plant Physiology 177, 633-651.

Ding Y, Jia Y, Shi Y, Zhang X, Song C, Gong Z, Yang S. 2018b. OST1mediated BTF3L phosphorylation positively regulates CBFs during plant cold responses. The EMBO Journal 37, e98228. 
Ding Y, Li H, Zhang X, Xie Q, Gong Z, Yang S. 2015. OST1 kinase modulates freezing tolerance by enhancing ICE1 stability in Arabidopsis. Developmental Cell 32, 278-289.

Ding Y, Lv J, Shi Y, Gao J, Hua J, Song C, Gong Z, Yang S. 2019. EGR2 phosphatase regulates OST1 kinase activity and freezing tolerance in Arabidopsis. The EMBO Journal 38, e99819.

Dissmeyer N, Schnittger A. 2011. The age of protein kinases. In: Dissmeyer N, Schnittger A, eds. Plant kinases. Methods in molecular biology (Methods and protocols), vol 779. Totowa, NJ, USA: Humana Press, 7-52.

Dong X, Yan Y, Jiang B, et al. 2020. The cold response regulator CBF1 promotes Arabidopsis hypocotyl growth at ambient temperatures. The EMBO Journal 39, e103630.

Du J, Jiang H, Sun X, et al. 2018. Auxin and gibberellins are required for the receptor-like kinase ERECTA regulated hypocotyl elongation in shade avoidance in Arabidopsis. Frontiers in Plant Science 9, 124.

Durek P, Schmidt R, Heazlewood JL, Jones A, MacLean D, Nagel A, Kersten B, Schulze WX. 2009. PhosPhAt: the Arabidopsis thaliana phosphorylation site database. An update. Nucleic Acids Research 38, D828-D834.

Eremina M, Rozhon W, Poppenberger B. 2016. Hormonal control of cold stress responses in plants. Cellular and Molecular Life Sciences $\mathbf{7 3}$ 797-810.

Fahad S, Bajwa AA, Nazir U, et al. 2017. Crop production under drought and heat stress: plant responses and management options. Frontiers in Plant Science 8, 1147.

Foreman J, Johansson H, Hornitschek P, Josse EM, Fankhauser C, Halliday KJ. 2011. Light receptor action is critical for maintaining plant biomass at warm ambient temperatures. The Plant Journal 65, 441-452.

Franklin KA, Lee SH, Patel D, et al. 2011. Phytochrome-interacting factor 4 (PIF4) regulates auxin biosynthesis at high temperature. Proceedings of the National Academy of Sciences, USA 108, 20231-20235.

Fujii Y, Tanaka H, Konno N, Ogasawara Y, Hamashima N, Tamura S, Hasegawa S, Hayasaki Y, Okajima K, Kodama Y. 2017. Phototropin perceives temperature based on the lifetime of its photoactivated state. Proceedings of the National Academy of Sciences, USA 114, 9206-9211.

Gangappa SN, Berriri S, Kumar SV. 2017. PIF4 coordinates thermosensory growth and immunity in Arabidopsis. Current Biology 27, 243-249.

Gao J, Zhang S, He WD, et al. 2017. Comparative phosphoproteomics reveals an important role of MKK2 in banana (Musa spp.) cold signal network. Scientific Reports 7, 40852.

Gray JE. 2007. Plant development: three steps for stomata. Current Biology 17, R213-R215.

Gray WM, Ostin A, Sandberg G, Romano CP, Estelle M. 2002. High temperature promotes auxin-mediated hypocotyl elongation in Arabidopsis. Proceedings of the National Academy of Sciences, USA 95, 7197-7202.

Haltenhof T, Kotte A, De Bortoli F, et al. 2020. A conserved kinasebased body-temperature sensor globally controls alternative splicing and gene expression. Molecular Cell 78, 57-69.e4.

Hasdai M, Weiss B, Levi A, Samach A, Porat R. 2006. Differential responses of Arabidopsis ecotypes to cold, chilling and freezing temperatures. Annals of Applied Biology 148, 113-120.

Hochstrasser M. 2010. Origin and function of ubiquitin-like protein conjugation mark. Nature 458, 422-429.

Hsu CC, Zhu Y, Arrington JV, Paez JS, Wang P, Zhu P, Chen IH, Zhu JK, Tao WA. 2018. Universal plant phosphoproteomics workflow and its application to tomato signaling in response to cold stress. Molecular \& Cellular Proteomics 17, 2068-2080.

Hu S, Ding Y, Zhu C. 2020. Sensitivity and responses of chloroplasts to heat stress in plants. Frontiers in Plant Science 11, 375

Hu Z, Li J, Ding S, Cheng F, Li X, Jiang Y, Yu J, Foyer CH, Shi K. 2021. The protein kinase CPK28 phosphorylates ascorbate peroxidase and enhances thermotolerance in tomato. Plant Physiology 186, 1302-1317.

Ibañez C, Delker C, Martinez C, et al. 2018. Brassinosteroids dominate hormonal regulation of plant thermomorphogenesis via BZR1. Current Biology 28, 303-310.e3.
Ibañez C, Poeschl Y, Peterson T, Bellstädt J, Denk K, Gogol-Döring A, Quint M, Delker C. 2017. Ambient temperature and genotype differentially affect developmental and phenotypic plasticity in Arabidopsis thaliana. BMC Plant Biology 17, 114.

Inda ME, Vandenbranden M, Fernández A, de Mendoza D, Ruysschaert JM, Cybulski LE. 2014. A lipid-mediated conformational switch modulates the thermosensing activity of DesK. Proceedings of the National Academy of Sciences, USA 111, 3579-3584.

Izumi M. 2019. Heat shock proteins support refolding and shredding of misfolded proteins. Plant Physiology 180, 1777-1778.

Jacott CN, Boden SA. 2020. Feeling the heat: developmental and molecular responses of wheat and barley to high ambient temperatures. Journal of Experimental Botany 71, 5740-5751.

Jin H, Zhu Z. 2019. Dark, light, and temperature: key players in plant morphogenesis. Plant Physiology 180, 1793-1802.

Jung JH, Domijan M, Klose C, et al. 2016. Phytochromes function as thermosensors in Arabidopsis. Science 354, 886-889.

Kim TW, Guan S, Sun Y, Deng Z, Tang W, Shang JX, Sun Y, Burlingame AL, Wang ZY. 2009. Brassinosteroid signal transduction from cell-surface receptor kinases to nuclear transcription factors. Nature Cell Biology 11, 1254-1260.

Kline-Jonakin KG, Barrett-Wilt GA, Sussman MR. 2011. Quantitative plant phosphoproteomics. Current Opinion in Plant Biology 14, 507-511.

Kobor MS, Venkatasubrahmanyam S, Meneghini MD, Gin JW, Jennings JL, Link AJ, Madhani HD, Rine J. 2004. A protein complex containing the conserved Swi2/Snf2-related ATPase Swr1p deposits histone variant H2A.Z into euchromatin. PLoS Biology 2, E131.

Koini MA, Alvey L, Allen T, Tilley CA, Harberd NP, Whitelam GC, Franklin KA. 2009. High temperature-mediated adaptations in plant architecture require the bHLH transcription factor PIF4. Current Biology 19, 408-413.

Kosová K, Vítámvás P, Planchon S, Renaut J, Vanková R, Prášil IT. 2013. Proteome analysis of cold response in spring and winter wheat (Triticum aestivum) crowns reveals similarities in stress adaptation and differences in regulatory processes between the growth habits. Journal of Proteome Research 12, 4830-4845.

Kostaki KI, Coupel-Ledru A, Bonnell VC, et al. 2020. Guard cells integrate light and temperature signals to control stomatal aperture. Plant Physiology 182, 1404-1419.

Kotak S, Larkindale J, Lee U, von Koskull-Döring P, Vierling E, Scharf KD. 2007. Complexity of the heat stress response in plants. Current Opinion in Plant Biology 10, 310-316.

Kumar SV, Wigge PA. 2010. H2A.Z-containing nucleosomes mediate the thermosensory response in Arabidopsis. Cell 140, 136-147.

Kuo MH, Allis CD. 1998. Roles of histone acetyltransferases and deacetylases in gene regulation. BioEssays 20, 615-626.

Lamers J, van der Meer T, Testerink C. 2020. How plants sense and respond to stressful environments. Plant Physiology 182, 1624-1635.

Larkindale J, Hall JD, Knight MR, Vierling E. 2005. Heat stress phenotypes of Arabidopsis mutants implicate multiple signaling pathways in the acquisition of thermotolerance. Plant Physiology 138, 882-897.

Larkindale J, Vierling E. 2008. Core genome responses involved in acclimation to high temperature. Plant Physiology 146, 748-761.

Legris M, Klose C, Burgie ES, Rojas CC, Neme M, Hiltbrunner A, Wigge PA, Schäfer E, Vierstra RD, Casal JJ. 2016. Phytochrome B integrates light and temperature signals in Arabidopsis. Science 354, 897-900. Legris M, Nieto C, Sellaro R, Prat S, Casal JJ. 2017. Perception and signalling of light and temperature cues in plants. The Plant Journal $\mathbf{9 0}$, 683-697.

Li B, Gao K, Ren H, Tang W. 2018. Molecular mechanisms governing plant responses to high temperatures. Journal of Integrative Plant Biology 60, 757-779.

Li H, Ding Y, Shi Y, Zhang X, Zhang S, Gong Z, Yang S. 2017. MPK3- and MPK6-mediated ICE1 phosphorylation negatively regulates ICE1 stability and freezing tolerance in Arabidopsis. Developmental Cell 43, 630-642.e4. 
Li J, Nam KH. 2002. Regulation of brassinosteroid signaling. Science $\mathbf{2 9 5}$ 1299-1301.

Li J, Terzaghi W, Gong Y, Li C, Ling JJ, Fan Y, Qin N, Gong X, Zhu D, Deng XW. 2020. Modulation of BIN2 kinase activity by HY5 controls hypocotyl elongation in the light. Nature Communications 11, 1592.

Lin J, Xu Y, Zhu Z. 2020. Emerging plant thermosensors: from RNA to protein. Trends in Plant Science 25, 1187-1189.

Ling Y, Serrano N, Gao G, et al. 2018. Thermopriming triggers splicing memory in Arabidopsis. Journal of Experimental Botany 69, 2659-2675.

Liu HT, Gao F, Li GL, Han JL, Liu DL, Sun DY, Zhou RG. 2008. The calmodulin-binding protein kinase 3 is part of heat-shock signal transduction in Arabidopsis thaliana. The Plant Journal 55, 760-773.

Liu J, Feng L, Li J, He Z. 2015. Genetic and epigenetic control of plant heat responses. Frontiers in Plant Science 6, 267.

Lobell DB, Gourdji SM. 2012. The influence of climate change on global crop productivity. Plant Physiology 160, 1686-1697.

Lorrain S, Allen T, Duek PD, Whitelam GC, Fankhauser C. 2008 Phytochrome-mediated inhibition of shade avoidance involves degradation of growth-promoting bHLH transcription factors. The Plant Journal 53, 312-323

Los DA, Murata N. 2004. Membrane fluidity and its roles in the perception of environmental signals. Biochimica et Biophysica Acta 1666, 142-157.

Lv X, Ge S, Jalal Ahammed G, Xiang X, Guo Z, Yu J, Zhou Y. 2017. Crosstalk between nitric oxide and MPK1/2 mediates cold acclimationinduced chilling tolerance in tomato. Plant \& Cell Physiology 58, 1963-1975.

Macho AP, Lozano-Durán R, Zipfel C. 2015. Importance of tyrosine phosphorylation in receptor kinase complexes. Trends in Plant Science 20 , 269-272.

Martínez C, Espinosa-Ruíz A, Lucas M, Bernardo-García S, FrancoZorrilla JM, Prat S. 2018. PIF 4-induced BR synthesis is critical to diurnal and thermomorphogenic growth. The EMBO Journal 37, e99552.

McLoughlin F, Kim M, Marshall RS, Vierstra RD, Vierling E. 2019 HSP101 interacts with the proteasome and promotes the clearance of ubiquitylated protein aggregates. Plant Physiology 180, 1829-1847.

Meng X, Wang H, He Y, Liu Y, Walker JC, Torii KU, Zhang S. 2013. A MAPK cascade downstream of ERECTA receptor-like protein kinase regulates Arabidopsis inflorescence architecture by promoting localized cell proliferation. The Plant Cell 24, 4948-4960.

Mishra SK, Tripp J, Winkelhaus S, Tschiersch B, Theres K, Nover L, Scharf KD. 2002. In the complex family of heat stress transcription factors, HsfA1 has a unique role as master regulator of thermotolerance in tomato. Genes \& Development 16, 1555-1567.

Miura K, Jin JB, Hasegawa PM. 2007. Sumoylation, a post-translationa regulatory process in plants. Current Opinion in Plant Biology 10, 495-502.

Mizoi J, Kanazawa N, Kidokoro S, Takahashi F, Qin F, Morimoto K, Shinozaki K, Yamaguchi-Shinozaki K. 2019. Heat-induced inhibition of phosphorylation of the stress-protective transcription factor DREB2A promotes thermotolerance of Arabidopsis thaliana. The Journal of Biologica Chemistry 294, 902-917.

Moellering ER, Muthan B, Benning C. 2010. Freezing tolerance in plants requires lipid remodeling at the outer chloroplast membrane. Science $\mathbf{3 3 0}$, 226-228.

Moller IM, Kristensen BK. 2004. Protein oxidation in plant mitochondria as a stress indicator. Photochemical \& Photobiological Sciences $\mathbf{3}$, 730-735

Morimoto K, Ohama N, Kidokoro S, et al. 2017. BPM-CUL3 E3 ligase modulates thermotolerance by facilitating negative regulatory domainmediated degradation of DREB2A in Arabidopsis. Proceedings of the National Academy of Sciences, USA 114, E8528-E8536.

Mustilli AC, Merlot S, Vavasseur A, Fenzi F, Giraudat J. 2002. Arabidopsis OST1 protein kinase mediates the regulation of stomatal aperture by abscisic acid and acts upstream of reactive oxygen species production. The Plant Cell 14, 3089-3099.

Nover L, Bharti K, Döring P, Mishra SK, Ganguli A, Scharf KD. 2001. Arabidopsis and the heat stress transcription factor world: how many heat stress transcription factors do we need? Cell Stress \& Chaperones 6 177-189.

Ohama N, Sato H, Shinozaki K, Yamaguchi-Shinozaki K. 2017. Transcriptional regulatory network of plant heat stress response. Trends in Plant Science 22, 53-65.

Paik I, Chen F, Ngoc Pham V, Zhu L, Kim JI, Huq E. 2019. A phyBPIF1-SPA1 kinase regulatory complex promotes photomorphogenesis in Arabidopsis. Nature Communications 10, 4216

Parent B, Millet EJ, Tardieu F. 2019. The use of thermal time in plant studies has a sound theoretical basis provided that confounding effects are avoided. Journal of Experimental Botany 70, 2359-2370.

Parent B, Tardieu F. 2012. Temperature responses of developmental processes have not been affected by breeding in different ecological areas for 17 crop species. New Phytologist 194, 760-774.

Park YJ, Lee HJ, Gil KE, Kim JY, Lee JH, Lee H, Cho HT, Vu LD, De Smet I, Park CM. 2019. Developmental programming of thermonastic leaf movement. Plant Physiology 180, 1185-1197.

Park YJ, Lee HJ, Ha JH, Kim JY, Park CM. 2017. COP1 conveys warm temperature information to hypocotyl thermomorphogenesis. New Phytologist 215, 269-280.

Patel D, Basu M, Hayes S, Majláth I, Hetherington FM, Tschaplinski TJ, Franklin KA. 2013. Temperature-dependent shade avoidance involves the receptor-like kinase ERECTA. The Plant Journal 73, 980-992.

Penfield S. 2008. Temperature perception and signal transduction in plants. New Phytologist 179, 615-628.

Peng P, Yan Z, Zhu Y, Li J. 2008. Regulation of the Arabidopsis GSK3-like kinase BRASSINOSTEROID-INSENSITIVE 2 through proteasome-mediated protein degradation. Molecular Plant 1, 338-346.

Pérez-Salamó I, Papdi C, Rigó G, et al. 2014. The heat shock factor A4A confers salt tolerance and is regulated by oxidative stress and the mitogenactivated protein kinases MPK3 and MPK6. Plant Physiology 165, 319-334

Prabakaran S, Lippens G, Steen H, Gunawardena J. 2012. Posttranslational modification: nature's escape from genetic imprisonment and the basis for dynamic information encoding. WIREs Mechanisms of Disease 4, 565-583.

Qu X, Zhao Z, Tian Z. 2017. ERECTA regulates cell elongation by activating auxin biosynthesis in Arabidopsis thaliana. Frontiers in Plant Science $\mathbf{8}$ 1688

Quint M, Delker C, Franklin KA, Wigge PA, Halliday KJ, van Zanten M. 2016. Molecular and genetic control of plant thermomorphogenesis. Nature Plants 2, 15190

Ramirez VE, Poppenberger B. 2017. MAP kinase signaling turns to ICE. Developmental Cell 43, 545-546.

Reindl A, Schöffl F, Schell J, Koncz C, Bakó L. 1997. Phosphorylation by a cyclin-dependent kinase modulates DNA binding of the Arabidopsis heat-shock transcription factor HSF1 in vitro. Plant Physiology 115, 93-100.

Russinova E, Borst JW, Kwaaitaal M, Caño-Delgado A, Yin Y, Chory J, de Vries SC. 2004. Heterodimerization and endocytosis of Arabidopsis brassinosteroid receptors BRI1 and AtSERK3 (BAK1). The Plant Cell $\mathbf{1 6}$ 3216-3229.

Sakuma Y, Maruyama K, Osakabe Y, Qin F, Seki M, Shinozaki K, Yamaguchi-Shinozaki K. 2006. Functional analysis of an Arabidopsis transcription factor, DREB2A, involved in drought-responsive gene expression. The Plant Cell 18, 1292-1309.

Samakovli D, Tichá T, Vavrdová T, et al. 2020. YODA-HSP90 module regulates phosphorylation-dependent inactivation of SPEECHLESS to control stomatal development under acute heat stress in Arabidopsis. Molecular Plant 13, 612-633.

Schlesinger MJ. 1990. Heat shock proteins. The Journal of Biological Chemistry 265, 12111-12114.

Schweighofe A, Meskiene I. 2015. Phosphatases in plants. In: Schulze W, eds. Plant phosphoproteomics. Methods in molecular biology, Vol. 1306 New York: Humana Press, 25-46.

Shen H, Zhong X, Zhao F, et al. 2015. Overexpression of receptor-like kinase ERECTA improves thermotolerance in rice and tomato. Nature Biotechnology 33, 996-1003. 
Shi Y, Ding Y, Yang S. 2018. Molecular regulation of CBF signaling in cold acclimation. Trends in Plant Science 23, 623-637.

Shin AY, Han YJ, Baek A, et al. 2016. Evidence that phytochrome functions as a protein kinase in plant light signalling. Nature Communications 7, 11545 .

Smoly I, Shemesh N, Ziv-Ukelson M, Ben-Zvi A, Yeger-Lotem E. 2017. An asymmetrically balanced organization of kinases versus phosphatases across eukaryotes determines their distinct impacts. PLoS Computational Biology 13, e1005221.

Song S, Wang H, Sun M, Tang J, Zheng B, Wang X, Tan YW. 2019. Reactive oxygen species-mediated BIN2 activity revealed by singlemolecule analysis. New Phytologist 223, 692-704.

Stavang JA, Gallego-Bartolomé J, Gómez MD, Yoshida S, Asami T, Olsen JE, García-Martínez JL, Alabadí D, Blázquez MA. 2009. Hormonal regulation of temperature-induced growth in Arabidopsis. The Plant Journal 60, 589-601.

Stocker TF, Qin D, Plattner G-K, Tignor MMB, Allen SK, Boschung J, Nauels A, Xia Y, Bex V, Midgley PM. 2013. Climate change - the physical science basis: working group I contribution to the fifth assessment report of the intergovernmental panel on climate change. Cambridge: Cambridge University Press.

Strasser R. 2016. Plant protein glycosylation. Glycobiology 26, 926-939.

Sun J, Qi L, Li Y, Chu J, Li C. 2012. PIF4-mediated activation of YUCCA8 expression integrates temperature into the auxin pathway in regulating Arabidopsis hypocotyl growth. PLoS Genetics 8, e1002594.

Sung DY, Kaplan F, Lee KJ, Guy CL. 2003. Acquired tolerance to temperature extremes. Trends in Plant Science 8, 179-187.

Teige M, Scheikl E, Eulgem T, Dóczi R, Ichimura K, Shinozaki K, Dangl JL, Hirt H. 2004. The MKK2 pathway mediates cold and salt stress signaling in Arabidopsis. Molecular Cell 15, 141-152.

Thomashow MF. 1999. PLANT COLD ACCLIMATION: freezing tolerance genes and regulatory mechanisms. Annual Review of Plant Physiology and Plant Molecular Biology 50, 571-599.

Thomashow MF. 2010. Molecular basis of plant cold acclimation: insights gained from studying the CBF cold response pathway. Plant Physiology 154, 571-577.

Torii KU, Mitsukawa N, Oosumi T, Matsuura Y, Yokoyama R, Whittier RF, Komeda Y. 1996. The Arabidopsis ERECTA gene encodes a putative receptor protein kinase with extracellular leucine-rich repeats. The Plant Cell 8, 735-746.

van der Woude LC, Perrella G, Snoek BL, et al. 2019. HISTONE DEACETYLASE 9 stimulates auxin-dependent thermomorphogenesis in Arabidopsis thaliana by mediating H2A.Z depletion. Proceedings of the National Academy of Sciences, USA 116, 25343-25354.

van Wijk KJ, Friso G, Walther D, Schulze WX. 2014. Meta-analysis of Arabidopsis thaliana phospho-proteomics data reveals compartmentalization of phosphorylation motifs. The Plant Cell 26, 2367-2389.

van Zanten M, Pons TL, Janssen JAM, Voesenek LACJ, Peeters AJM. 2010. On the relevance and control of leaf angle. Critical Reviews in Plant Sciences 29, 300-316.

van Zanten M, Snoek LB, Proveniers MC, Peeters AJ. 2009a. The many functions of ERECTA. Trends in Plant Science 14, 214-218.

van Zanten M, Voesenek LA, Peeters AJ, Millenaar FF. $2009 \mathrm{~b}$. Hormone- and light-mediated regulation of heat-induced differential petiole growth in Arabidopsis. Plant Physiology 151, 1446-1458.

Vu LD, Gevaert K, De Smet I. 2018a. Protein language: post-translational modifications talking to each other. Trends in Plant Science 23, 1068-1080. Vu LD, Stes E, Van Bel M, Nelissen H, Maddelein D, Inzé D, Coppens F, Martens L, Gevaert K, De Smet I. 2016. Up-to-date workflow for plant (phospho)proteomics identifies differential drought-responsive phosphorylation events in maize leaves. Journal of Proteome Research 15, 4304-4317.

Vu LD, Xu X, Gevaert K, De Smet I. 2019. Developmental plasticity at high temperature. Plant Physiology 181, 399-411.
Vu LD, Xu X, Zhu T, et al. 2021. The membrane-localized protein kinase MAP4K4/TOT3 regulates thermomorphogenesis. Nature Communications 12, 2842

Vu LD, Zhu T, Verstraeten I, van de Cotte B, Gevaert K, De Smet I; International Wheat Genome Sequencing Consortium. 2018b. Temperatureinduced changes in the wheat phosphoproteome reveal temperatureregulated interconversion of phosphoforms. Journal of Experimental Botany 69, 4609-4624.

Wahid A, Gelani S, Ashraf M, Foolad MR. 2007. Heat tolerance in plants: an overview. Environmental and Experimental Botany 61, 199-223.

Wang F, Zhang L, Chen X, et al. 2019. SIHY5 integrates temperature, light, and hormone signaling to balance plant growth and cold tolerance. Plant Physiology 179, 749-760.

Wang H, Chevalier D, Larue C, Cho SK, Walkera JC. 2007. The protein phosphatases and protein kinases of Arabidopsis thaliana. The Arabidopsis Book 5, e0106.

Wang W, Paik I, Kim J, Hou X, Sung S, Huq E. 2021. Direct phosphorylation of HY5 by SPA kinases to regulate photomorphogenesis in Arabidopsis. New Phytologist 230, 2311-2326.

Wang ZY, Nakano T, Gendron J, et al. 2002. Nuclear-localized BZR1 mediates brassinosteroid-induced growth and feedback suppression of brassinosteroid biosynthesis. Developmental Cell 2, 505-513.

Wanner LA, Junttila O. 1999. Cold-induced freezing tolerance in Arabidopsis. Plant Physiology 120, 391-400.

Wu C. 1995. HEAT SHOCK TRANSCRIPTION FACTORS: structure and regulation translocation, higher order assembly, and protein degradation. Annual Review of Cell and Developmental Biology 11, 441-469.

Xu J, Zhang S. 2015. Mitogen-activated protein kinase cascades in signaling plant growth and development. Trends in Plant Science 20, 56-64. Yang T, Shubho C, Yang L, Du L, Poovaiah BW. 2020. Molecular regulation of CBF signaling in cold acclimation. The Journal of Biological Chemistry 285, 7119-7126.

Ye K, Li H, Ding Y, Shi Y, Song C, Gong Z, Yang S. 2019 BRASSINOSTEROID-INSENSITIVE2 negatively regulates the stability of transcription factor ICE1 in response to cold stress in Arabidopsis. The Plant Cell 31, 2682-2696.

Yeh CH, Kaplinsky NJ, Hu C, Charng YY. 2012. Some like it hot, some like it warm: phenotyping to explore thermotolerance diversity. Plant Science 195, 10-23.

Yin Y, Wang ZY, Mora-Garcia S, Li J, Yoshida S, Asami T, Chory J. 2002. BES1 accumulates in the nucleus in response to brassinosteroids to regulate gene expression and promote stem elongation. Cell 109, 181-191.

Yoo CY, Miura K, Jin JB, Lee J, Park HC, Salt DE, Yun DJ, Bressan RA, Hasegawa PM. 2006. SIZ1 small ubiquitin-like modifier E3 ligase facilitates basal thermotolerance in Arabidopsis independent of salicylic acid. Plant Physiology 142, 1548-1558.

Yoshida T, Ohama N, Nakajima J, et al. 2011. Arabidopsis HsfA1 transcription factors function as the main positive regulators in heat shockresponsive gene expression. Molecular Genetics and Genomics 286 , 321-332.

Zhao C, Wang P, Si T, et al. 2017. MAP kinase cascades regulate the cold response by modulating ICE1 protein stability. Developmental Cell $\mathbf{4 3}$, 618-629.e5.

Zhu T, De Lima CFF, De Smet I. 2021. The heat is on: how crop growth, development and yield respond to high temperature. Journal of Experimental Botany 72, 7359-7373.

Zhu W, Zhou H, Lin F, Zhao X, Jiang Y, Xu D, Deng XW. 2020. COLDREGULATED GENE27 integrates signals from light and the circadian clock to promote hypocotyl growth in Arabidopsis. The Plant Cell 32 3155-3169.

Zuther E, Schulz E, Childs LH, Hincha DK. 2012. Clinal variation in the non-acclimated and cold-acclimated freezing tolerance of Arabidopsis thaliana accessions. Plant, Cell \& Environment 35, 1860-1878. 